\title{
Relationship between clinical and histopathological features of patients undergoing cholecystectomy
}

\author{
Sami Akbulut ${ }^{1,2}$, Yusuf Yagmur², Hamdi Sakarya², Zeynep Sener Bahce², Serdar Gumus², Nilgun Sogutcu ${ }^{3}$ \\ ${ }^{1}$ Department of Surgery and Liver Transplant Institute, Inonu University Faculty of Medicine, Malatya, Turkey \\ 2Department of Surgery, Diyarbakir Education and Research Hospital, Diyarbakir, Turkey \\ ${ }^{3}$ Department of Pathology, Diyarbakir Education and Research Hospital, Diyarbakir, Turkey
}

Gastroenterology Rev 2020; 15 (2): 131-137

DOI: https://doi.org/10.5114/pg.2019.86772

Key words: cholelithiasis, cholecystitis, unusual findings, gallbladder cancer.

Address for correspondence: Sami Akbulut, Assos. Prof, FICS, FACS, Department of Surgery and Liver Transplant Institute, Inonu University Faculty of Medicine, Elazig Yolu 10. Km Malatya 44280, Turkey, phone: +90 422-3410660, fax: +90 422-3410036, e-mail: akbulutsami@gmail.com

\begin{abstract}
Introduction: Cholelithiasis is most common disease of the gallbladder and cholecystectomy is the one of the most performed surgical procedure worldwide.

Aim: To assess the relationship between the demographic, biochemical, and histopathological variables of patients who underwent cholecystectomy.

Material and methods: Demographic, biochemical, and histopathological data of 5077 patients undergoing cholecystectomy were compared in terms of two different aspects: open cholecystectomy (OC group; $n=2090$ ) versus laparoscopic cholecystectomy (LC group; $n=2987)$, and an elective group $(n=4814)$ versus an emergency group $(n=263)$.

Results: A total of 5077 patients aged between 13 and 97 years were included in the study. Aspartate aminotransferase (AST) levels, alanine aminotransferase (ALT) levels, mean platelet volume, and prevalence of acute/chronic cholecystitis were significantly higher in the LC group than in the OC group. On the other hand, age, direct bilirubin level, thrombocyte count, and prevalence of gallbladder cancer/gangrenous cholecystitis were significantly higher in the OC group than in the LC group. Levels of AST, ALT, white blood cells, neutrophils, and some prevalence of acute/chronic active cholecystitis were higher in the emergency group than in the elective group. On the other hand, the lymphocyte count and prevalence of chronic cholecystitis/hyperplastic polyps were higher in the elective group than in the emergency group. Histopathological analysis identified 32 patients with malignant gallbladder cancer as follows: adenocarcinoma $(n=21)$, mucinous adenocarcinoma $(n=3)$, papillary adenocarcinoma $(n=3)$, adenosquamous carcinoma $(n=1)$, clear cell adenocarcinoma $(n=2)$, squamous carcinoma $(n=1)$, and hepatocellular carcinoma metastasis $(n=1)$.

Conclusions: Even when the appearance of gallbladder specimens is normal, histopathological assessment allows for early diagnosis of many unusual findings such as gallbladder cancer.
\end{abstract}

\section{Introduction}

Cholelithiasis is present in $5 \%$ to $22 \%$ of Western populations, and $13-22 \%$ of them are symptomatic throughout their lifetime. Complicated cholelithiasis has a $5 \%$ risk of causing lifelong choledocholithiasis, acute cholecystitis, acute pancreatitis, or cholangitis $[1,2]$. Acute cholecystitis occurs in $10-20 \%$ of those with untreated cholelithiasis [3, 4]. Repeatedly symptomatic patients with acute cholecystitis, who are sent home without surgery, show biliary colic in $70 \%$, biliary obstruction in $24 \%$, and pancreatitis in $6 \%$ of cases [5]. Despite this frequency, important discussions continue into the diagnosis and treatment of acute cholecystitis, including the timing of surgery, the type of surgery, and the role of cholecystostomy in high-risk patients [3]. Since their publication in 2007, the Tokyo guidelines have set out objective parameters for the diagnosis of acute cholecystitis and helped improve our knowledge of acute cholecystitis [6]. The Tokyo Guidelines Revision Committee concluded that acute cholecystitis should be suspected when Murphy's sign, local inflammatory findings in the gallbladder such as right upper quadrant abdominal pain and tenderness, fever, and systemic inflammatory reaction findings detected by blood tests are present, but that a definitive diagnosis of acute cholecystitis can be made only 
on the basis of imaging techniques such as ultrasonography (US), computed tomography (CT), magnetic resonance cholangiopancreatography $(\mathrm{MRCP})$, or scintigraphy [7].

Laparoscopic cholecystectomy (LC) has become the gold standard in the treatment of cholelithiasis, with the introduction of LC in France in 1987 and in the USA in 1988. Cholecystectomy is the first treatment option in symptomatic cholelithiasis [8]. Indications for a laparoscopic approach to the gallbladder and biliary tree include symptomatic cholelithiasis, biliary dyskinesia, acute cholecystitis, and complications related to common bile duct stones including pancreatitis with few relative or absolute contraindications [8].

\section{Aim}

The primary aim of this study was to assess the relationship between the demographic, biochemical, and histopathological variables of patients undergoing cholecystectomy. A secondary aim was to identify the histopathological findings in especially malignant changes in gallbladder specimens.

\section{Material and methods}

Between February 2005 and December 2013 the data of 6004 patients undergoing laparoscopic or open cholecystectomy for cholelithiasis/cholecystitis in Diyarbakir Education and Research Hospital and Diyarbakir State Hospital were retrospectively reviewed. Patients who had complete demographic, clinical, and biochemical characteristics and histopathological findings in their records were included in the study $(n=5077)$. Patients with incomplete records were excluded from the study $(n=927)$. The patients were compared in two different aspects. First, the patients were divided into two groups by surgical technique: open (open cholecystectomy (OC) group; $n=2090$ ) versus laparoscopic cholecystectomy (laparoscopic cholecystectomy group; $n=2987)$. Power analysis $(1-\beta)$ for this comparison was $100 \%(\alpha=0.05$, effect size $=$ 0.3 , two-tailed, critical $t=1.96$, noncentrality parameter $=10.51)$. Second, the patients were divided into two groups based on the timing of the surgery: elective (elective group; $n=4814$ ) versus emergency cholecystectomy (emergency group, EmC; $n=263$ ). Power analysis for this comparison was $99.9 \%(\alpha=0.05$, effect size $=0.3$, two tailed, critical $t=1.96$, noncentrality parameter $=4.73$ ).

Groups were compared in terms of age, sex, alanine aminotransferase (ALT), aspartate aminotransferase (AST), direct bilirubin (DBil), white blood cell (WBC), neutrophil, lymphocyte, thrombocyte, mean platelet volume (MPV), and histopathological examination findings. Acute cholecystitis was diagnosed by the presence of clinical findings (Murphy's sign, right upper quadrant pain, and fever) and biochemical measurements (leukocytosis, elevated liver function tests, and radiological findings). Radiological findings in acute cholecystitis were as follows: impacted gallbladder stone in the cystic duct, positive sonographic Murphy's sign, increased gallbladder wall thickness, distension of the gallbladder, pericholecystic fluid collection, and mural or mucosal hyperenhancement.

The OC procedure was used as the main surgical option in the treatment until July 2009, and almost all the patients underwent LC since that date. In this regard, the launch of the Diyarbakir Education and Research Hospital in 2010 has been effective. The OC was performed on 104 of 263 patients who underwent EmC, and a significant number of these operations were performed before 2009. After 2009, OC was only preferred under the following conditions: previous upper abdominal surgery, inexperience of the surgeon, difficult Calot's triangle dissection, or severe cardiac or pulmonary dysfunction. OC was performed using a midline or subcostal incision depending on the surgeon's experience. Drains were used in patients who underwent emergency surgery or had bleeding during dissection. Considering the clinical findings or the timing of the surgery, cefazolin, ampicillin, or ceftriaxone was used for antibiotic prophylaxis. Uncomplicated cases were discharged on the second postoperative day. LC in patients with acute, gangrenous, or chronic active cholecystitis was performed within $72 \mathrm{~h}$ of the onset of symptoms except in patients who underwent percutaneous cholecystostomy. Elective cholecystectomy was delayed to 4-6 weeks after percutaneous cholecystostomy to allow resolution of inflammation and to improve the patient's comorbid condition. Laparoscopic cholecystectomy was performed using intraperitoneal $\mathrm{CO}_{2}$ insufflation for a $12-14 \mathrm{~mm} \mathrm{Hg}$ pneumoperitoneum. Laparoscopic cholecystectomy was routinely performed using a standard four-port LC technique. In this technique, a 10-mm infraumbilical port, a 10-mm subxiphoid port, and two 5-mm subcostal ports were used. Because this study is a retrospective clinical study, local Ethics Committee approval was not received.

\section{Statistical analysis}

The statistical analyses were performed using IBM SPSS Statistics (v25.0; IBM Corp., Armonk, NY, USA). The quantitative variables were expressed as mean \pm standard deviation $( \pm \mathrm{SD})$ or median and range (minimum-maximum); the qualitative variables were reported as number and percentage (\%). Kolmogorov-Smirnov tests were used to assess normality of quantitative vari- 
able distribution. Mann-Whitney $U$ tests were used to compare quantitative variables. Pearson's $\chi^{2}$ tests were used for comparison of qualitative variables. A $p$-value of less than 0.05 was considered statistically significant.

\section{Results}

The demographic and clinical data of 5077 patients were retrospectively reviewed. 946 were male and 4131 were female patients, with ages ranging from 13 to 97 years (median: 47 , mean \pm SD: $47.9 \pm 15.4$ years). The female-to-male ratio was found to be 4.36 .

Elective cholecystectomy was performed in 4814 patients, and emergency cholecystectomy was performed in the remaining 263 patients. Age $(p<0.001)$, AST $(p<0.001), \operatorname{ALT}(p=0.008), \operatorname{WBC}(p<0.001)$, neutrophil $(p<0.001)$, and some histopathological findings (acute and chronic active cholecystitis; $p<0.001$ ) were significantly different in the emergency group compared to the elective group. On the other hand, lymphocyte count $(p<0.001)$ and some histopathological findings (chronic cholecystitis, hyperplastic polyps; $p<0.001$ ) were significantly different in the elective group compared to the emergency group. The rate of elective surgery was higher in women (95.9 vs. 90.1\%) $(p<0.001)$. There were no significant differences between the groups in terms of DBil $(p=0.317)$, thrombocytes $(p=0.613)$, and MPV $(p=0.232)$ (Table I).

Laparoscopic cholecystectomy was performed in 2987 patients, and OC was performed in the remaining 2090 patients. The median age of patients in the open and laparoscopic groups were 47 and 46 years, respectively $(p=0.001)$. The AST $(p=0.002)$, ALT $(p<0.001)$, MPV $(p<0.001)$, and some histopathologic findings (acute and chronic cholecystitis) were significantly different in the laparoscopic group compared to the open group. On the other hand, age $(p=0.001)$, DBil $(p<0.001)$, thrombocyte $(p<0.001)$, and some histopathologic findings (gallbladder cancer, gangrenous cholecystitis) were significantly different in the open group compared to the laparoscopic group. There were no significant differences between the groups in terms of clinical presentation ( $p=0.583)$, sex $(p=0.320)$, WBC $(p=0.951)$, neutrophil $(p=0.166)$, and lymphocyte $(p=0.115)$ values (Table II).

Gallbladder specimens were routinely sent to the pathology laboratory for histopathological examination. Histopathological analysis identified the 5077 patients as follows: chronic cholecystitis $(n=4764)$, chronic active cholecystitis $(n=114)$, acute cholecystitis $(n=111)$, gangrenous cholecystitis $(n=38)$, gallbladder cancer $(n=32)$, hyperplastic polyps $(n=14)$, tubular adenoma $(n=3)$, and eosinophilic cholecystitis $(n=1)$. The histopathological details of the 32 patients with gallbladder
Table I. Comparison of elective and emergency cholecystectomy groups in terms of demographic, clinical, and histopathological features

\begin{tabular}{|c|c|c|c|}
\hline Patients' features & $\begin{array}{c}\text { Elective } \\
(n=4814)\end{array}$ & $\begin{array}{c}\text { Emergency } \\
(n=263)\end{array}$ & $P$-value \\
\hline Age [years]: & & & $<0.001$ \\
\hline Mean \pm SD & $47.6 \pm 15.2$ & $52.5 \pm 16.9$ & \\
\hline Median (min.-max.) & 46 (13-97) & $53(18-90)$ & \\
\hline Sex, $n(\%):$ & & & $<0.001$ \\
\hline Male & $852(90.1)$ & $94(9.9)$ & \\
\hline Female & 3962 (95.9) & $169(4.1)$ & \\
\hline Surgical approach, $n$ (\%): & & & 0.583 \\
\hline Open & $1986(95.0)$ & $104(5.0)$ & \\
\hline Lap & $2828(94.7)$ & $159(5.3)$ & \\
\hline AST: & & & $<0.001$ \\
\hline Mean \pm SD & $36.5 \pm 59.4$ & $40.8 \pm 53.1$ & \\
\hline Median (min.-max.) & $22(10-898)$ & $24(10-446)$ & \\
\hline ALT: & & & 0.008 \\
\hline Mean \pm SD & $41.5 \pm 67.8$ & $47.6 \pm 74.9$ & \\
\hline Median (min.-max.) & $22(10-914)$ & $25(10-679)$ & \\
\hline DBil: & & & 0.317 \\
\hline Mean \pm SD & $0.38 \pm 0.42$ & $0.44 \pm 0.64$ & \\
\hline Median (min.-max.) & $0.2(0.1-6.5)$ & $0.2(0.1-6.5)$ & \\
\hline WBC: & & & $<0.001$ \\
\hline Mean \pm SD & $8.5 \pm 2.9$ & $11.1 \pm 4.6$ & \\
\hline Median (min.-max.) & $7.9(2.6-29.8)$ & $10(2.8-28.2)$ & \\
\hline Neutrophil: & & & $<0.001$ \\
\hline Mean \pm SD & $5.4 \pm 2.7$ & $7.9 \pm 4.2$ & \\
\hline Median (min.-max.) & $4.8(1.1-27)$ & $6.6(1.4-24.8)$ & \\
\hline Lymphocyte: & $<0.001$ & & \\
\hline Mean \pm SD & $2.2 \pm 0.8$ & $2.1 \pm 0.9$ & \\
\hline Median (min.-max.) & $2.1(0.1-6.9)$ & $1.9(0.2-6.8)$ & \\
\hline Thrombocytes: & 0.613 & & \\
\hline Mean \pm SD & $274 \pm 77$ & $280 \pm 85$ & \\
\hline Median (min.-max.) & $268(50-835)$ & $272(102-606)$ & \\
\hline MPV: & & & 0.232 \\
\hline Mean \pm SD & $8.8 \pm 1.4$ & $9.0 \pm 1.5$ & \\
\hline Median (min.-max.) & $8.6(5.7-10.1)$ & $8.8(5.7-13.5)$ & \\
\hline \multicolumn{4}{|l|}{ Histopathological findings: } \\
\hline Acute cholecystitis & 0 & 111 & \\
\hline Gallbladder cancer & 32 & 0 & \\
\hline $\begin{array}{l}\text { Chronic active } \\
\text { cholecystitis }\end{array}$ & 0 & 114 & \\
\hline Chronic cholecystitis & 4764 & 0 & \\
\hline Gangrenous cholecystitis & 0 & 38 & \\
\hline Hyperplastic polyps & 14 & 0 & \\
\hline Tubular adenoma & 3 & 0 & \\
\hline Eosinophilic cholecystitis & 1 & 0 & \\
\hline
\end{tabular}


Table II. Comparison of open and laparoscopic cholecystectomy groups in terms of demographic, clinic, and histopathological features

\begin{tabular}{lccc} 
Patients' features & $\begin{array}{c}\text { Open } \\
(n=2090)\end{array}$ & $\begin{array}{c}\text { Lap } \\
(n=2987)\end{array}$ & $P$-value \\
\hline Age [years]: & & 0.001 \\
\hline Mean \pm SD & $48.9 \pm 15.6$ & $47.2 \pm 15$ & \\
\hline Median (min.-max.) & $47(13-92)$ & $46(15-97)$ & \\
\hline Sex, $n$ (\%): & & 0.320 \\
\hline Male & $403(42.6)$ & $543(57.4)$ & \\
\hline Female & $1687(40.8)$ & $2444(59.2)$ & \\
\hline Clinical presentation, $n(\%):$ & & 0.607 \\
\hline Elective & $1986(41.3)$ & $2828(58.7)$ & \\
\hline Emergency & $104(39.5)$ & $159(60.5)$ & \\
\hline AST: & & & 0.002 \\
\hline Mean \pm SD & $33.9 \pm 53.1$ & $38.7 \pm 628$ & \\
\hline Median (min.-max.) & $22(10-878)$ & $23(10-898)$ & \\
\hline ALT: & & & $<0.001$ \\
\hline Mean $\pm S D$ & $37.7 \pm 58.5$ & $44.8 \pm 74.0$ & \\
\hline Median (min.-max.) & $21(10-750)$ & $23(10-914)$ & \\
\hline DBil: & & & $<0.001$ \\
\hline Mean $\pm S D$ & $0.43 \pm 0.45$ & $0.35 \pm 0.4$ & \\
\hline Median (min.-max.) & $0.3(0.1-6.5)$ & $0.2(0.1-6.5)$ & \\
\hline WBC: & & & 0.951 \\
\hline Mean $\pm S D$ & $8.6 \pm 3.2$ & $8.6 \pm 3.1$ & \\
\hline Median (min.-max.) & $8(2.8-29.7)$ & $8(2.6-29.8)$ & \\
\hline Neutrophil: & & & 0.166 \\
\hline Mean $\pm S D$ & $5.6 \pm 2.9$ & $5.5 \pm 2.8$ & \\
\hline Median (min.-max.) & $4.9(1.2-27)$ & $4.8(1.1-24.8)$ & \\
\hline Lymphocyte: & & & \\
\hline Mean $\pm S D$ & $2.1 \pm 0.8$ & $2.2 \pm 0.8$ & \\
\hline Median (min.-max.) & $2.1(0.1-6.9)$ & $2.1(0.1-6.8)$ & \\
\hline
\end{tabular}

cancer were as follows: adenocarcinoma $(n=21)$, mucinous adenocarcinoma $(n=3)$, papillary adenocarcinoma $(n=3)$, adenosquamous carcinoma $(n=1)$, clear cell adenocarcinoma $(n=2)$, squamous carcinoma $(n=1)$, and hepatocellular carcinoma (HCC) metastasis $(n=1)$. Elective surgery was applied to all of the gallbladder tumours in this study. Twenty-four of 32 patients were diagnosed with gallbladder cancer incidentally. Because of the suspicion of a gallbladder tumour in the preoperative $\mathrm{CT}$ of the remaining eight patients, the open surgical procedure was preferred. The gallbladders of seven of these cancer patients were removed along with an adjacent $1-2 \mathrm{~cm}$ of liver tissue. In one patient, only the gallbladder was removed because there were other HCC foci in the liver. The cholecystectomy procedure was curative in 29 patients, whereas in two patients, radical resection was required, and these patients were referred to another experienced centre.

\begin{tabular}{|c|c|c|c|}
\hline Patients' features & $\begin{array}{c}\text { Open } \\
(n=2090)\end{array}$ & $\begin{array}{c}\text { Lap } \\
(n=2987)\end{array}$ & $P$-value \\
\hline Thrombocytes: & & & $<0.001$ \\
\hline Mean \pm SD & $288 \pm 81.9$ & $264.9 \pm 73.2$ & \\
\hline Median (min.-max.) & $284(50-835)$ & $257(70-768)$ & \\
\hline MPV: & & & $<0.001$ \\
\hline Mean \pm SD & $8.3 \pm 1.2$ & $9.2 \pm 1.4$ & \\
\hline Median (min.-max.) & $8.2(5.7-13.7)$ & $9.2(5.7-15.8)$ & \\
\hline \multicolumn{4}{|l|}{ Histopathological findings: } \\
\hline Acute cholecystitis & 19 & 92 & \\
\hline Gallbladder cancer: & 20 & 12 & \\
\hline Adeno Ca & 12 & 9 & \\
\hline $\begin{array}{l}\text { Mucinous } \\
\text { adenocarcinoma }\end{array}$ & 3 & 0 & \\
\hline $\begin{array}{l}\text { Adenosquamous } \\
\mathrm{Ca}\end{array}$ & 0 & 1 & \\
\hline $\begin{array}{l}\text { Papillary } \\
\text { adenocarcinoma }\end{array}$ & 2 & 1 & \\
\hline $\begin{array}{l}\text { Clear cell } \\
\text { adenocarcinoma }\end{array}$ & 2 & 0 & \\
\hline Squamous Ca & 0 & 1 & \\
\hline HCC metastasis & 1 & 0 & \\
\hline $\begin{array}{l}\text { Chronic active } \\
\text { cholecystitis }\end{array}$ & 57 & 57 & \\
\hline Chronic cholecystitis & 1952 & 2812 & \\
\hline $\begin{array}{l}\text { Gangrenous } \\
\text { cholecystitis }\end{array}$ & 28 & 10 & \\
\hline Hyperplastic polyps & 11 & 3 & \\
\hline Tubular adenoma & 2 & 1 & \\
\hline $\begin{array}{l}\text { Eosinophilic } \\
\text { cholecystitis }\end{array}$ & 1 & 0 & \\
\hline
\end{tabular}

\section{Discussion}

Cholecystectomy is one of the most common surgical procedures in the world [9]. In developed countries, $10-15 \%$ of the adult population has cholelithiasis. According to the Third National Health and Nutrition Examination Survey, in the United States, 14.2 million women and 6.3 million men in the 20-74-year age group have gallbladder disease and $18.8 \%$ of women and $9.5 \%$ of the males in Italy have cholelithiasis [3].

Initially, the rates of conversion to open cholecystectomy in patients with acute cholecystitis ranged from 18 to $28 \%$. Therefore, LC was not recommended at first due to high complication rates $[10,11]$. The development of laparoscopic instruments and increased laparoscopic experience among surgeons has led to the introduction of LC as a safe method in patients with acute cholecystitis [10]. 
In most people with cholelithiasis, stones are identified coincidentally as a result of investigations for other conditions with no symptoms present. However, there are differing approaches as to how people are managed once asymptomatic cholelithiasis has been diagnosed. People with asymptomatic cholelithiasis found in a normal gallbladder should be reassured that they do not need treatment unless they develop symptoms. In our practice, almost all people are offered cholecystectomy to prevent developing symptoms and complications. In our view, surgeons do not prefer to delay surgery until stones develop and cause symptoms, and therefore offer LC.

In the diagnosis of cholelithiasis, liver function tests and ultrasound in people with suspected cholelithiasis and those with abdominal or gastrointestinal symptoms that have been unresponsive to previous management are recommended by the Internal Clinical Guidelines Programme within the Centre for Clinical Practice (CCP) at the National Institute for Health and Care Excellence (NICE, UK). If ultrasound has not detected common bile duct stones but the bile duct is dilated and/or the liver function test is abnormal, magnetic resonance cholangiopancreatography (MRCP) is considered. If MRCP is not sufficient for diagnosis, endoscopic ultrasound is recommended [12]. Although abdominal ultrasound is a very safe diagnostic method, it is relatively low in sensitivity and specificity in the diagnosis of acute cholecystitis. Hepatobiliary iminodiacetic acid scan (HIDA scan) has high sensitivity and specificity in the diagnosis of acute cholecystitis [3].

The NICE group recommends early LC within one week of diagnosis of acute cholecystitis and percutaneous cholecystostomy to manage gallbladder empyema if surgery is contraindicated at presentation and conservative management is unsuccessful [12]. Early LC is preferred due to an overall better quality of life, lower morbidity rates, and lower hospital cost [13]. The LC within $72 \mathrm{~h}$ is recommended. Furthermore, early cholecystectomy - defined as within 1 week of symptom onset - has been found to reduce cholelithiasis-related complications, shorten hospital stays, and lower costs. If the patient cannot undergo surgery, percutaneous cholecystostomy or other novel endoscopic gallbladder drainage interventions can be used [14].

Early LC is performed within $72 \mathrm{~h}$ of diagnosis of acute cholecystitis. Delayed LC is performed between 7 days and 45 days after the initial diagnosis and at least 6 weeks after the initial diagnosis. In acute cholecystitis, early LC is preferred to delayed LC as long as symptoms are within 10 days of the onset of symptoms. Delayed LC after 45 days is better in patients with symptoms for more than 10 days. Early LC should be per- formed immediately, but it can be done within 10 days of the onset of symptoms [3]. We did not experience intraoperative complications in any of the acute cholecystitis cases with early LC or OC within $72 \mathrm{~h}$ of the onset of symptoms. However, hospital stay and simple wound infection rates in patients who underwent early OC were higher than those of patients who underwent early LC.

According to the Tokyo Guidelines, optimal treatment of acute cholecystitis is an early laparoscopic surgery, especially less than $72 \mathrm{~h}$ after the onset of symptoms [15]. The LC done in acute cholecystitis after $72 \mathrm{~h}$ has a long operating time, increased blood loss, high OC conversion rate, and long-term hospitalisation [16]. Previous studies have suggested early OC because of its safety, low cost, and the advantages of an early return to normal activities [17-19]. Subsequent randomised clinical trials suggest an early LC procedure because of an early recovery, short hospital stay, and overall cost advantages. These results show that early LC is safe for acute cholecystitis patients and can be performed in a routine application [17].

According to the World Society of Emergency Surgery consensus meeting, the laparoscopic approach should be performed in acute cholecystitis as an initial therapy as long as there is no anaesthetic contraindication or septic shock [17]. The LC is safe, affordable, has low complication rates, and shortens hospital stay in patients with acute cholecystitis. LC is safe and suitable for children with Child-Pugh class A and B cirrhosis, patients aged $>80$ years, or high-risk acute cholecystitis such as in pregnant women [3]. Laparoscopic or open subtotal cholecystectomy is an appropriate treatment option in the case of severe inflammation, chronic liver disease, portal hypertension, adhesion, and major vasculobiliary anomalies.

Percutaneous cholecystostomy can be applied as an alternative in patients with severe co-morbidity, patients unsuitable for emergency surgery, and after failed conservative treatment $[3,20]$. The treatment for critically ill patients with acute cholecystitis is still difficult to decide, even today. In order to avoid the risks of cholecystectomy, percutaneous cholecystostomy is recommended because of the advantages of drainage with cholecystostomy in patients with critical acute cholecystitis [20]. Cholecystectomy is usually performed several days after percutaneous transhepatic biliary drainage. Early cholecystectomy is recommended if the patient's condition has improved after drainage and complications have not developed in the patient $[17,18]$. Cholecystectomy should be considered after percutaneous gallbladder drainage and medical treatment in patients with high-risk acute cholecystitis [19-21]. The elderly and critically ill patients who undergo LC for acute cho- 
lecystitis may have a high risk of conversion, complication, or death. Percutaneous cholecystostomy is recommended in the treatment of this group of patients. Although percutaneous cholecystostomy is available in many guidelines in the treatment of acute cholecystitis, only the Tokyo Guidelines provide well-defined criteria $[22,23]$. The time between the occurrence of symptoms and transhepatic catheter placement varies considerably at different centres. It is not clear how long after the catheter is withdrawn the cholecystectomy should be performed. These variabilities make it difficult to compare the results of percutaneous cholecystostomy from various centres [24]. Until the middle of 2013, there was no radiologist experienced in interventional radiological procedures such as percutaneous cholecystostomy in our clinic. Therefore, in patients without serious risk factors, we routinely preferred to perform early cholecystectomy or cooling down therapy.

In developed countries and in Turkey, the laparoscopic approach is preferred currently because of reduced pain, shorter hospital stay, reduced morbidity, and better cosmetic results. The LC is now used in almost all cases. Although laparoscopy is the gold standard, the carbon dioxide used during LC is high in concentration and causes hypercapnia and respiratory acidosis. The intraabdominal pressure of LC has been shown to reduce blood flow to the liver through laser-Doppler techniques. In a study it was shown that a $12-\mathrm{mm} \mathrm{Hg}$ pneumoperitoneum reduces both hepatic and gastric microcirculation and can cause splenic ischaemia [25]. Several studies have shown that liver function tests after LC are elevated and this may be due to hepatic hypoperfusion and ischaemia [26].

After LC, occasionally incidental gallbladder cancer is diagnosed. Gallbladder cancer is rare, aggressive, and causes higher mortality. It is the fifth most common of the gastrointestinal tumours [27]. Only 30\% of gallbladder cancers are suspected preoperatively, and the remaining $70 \%$ are incidentally diagnosed during or after surgery by pathological diagnosis. The estimated incidence of cancer diagnosis after cholecystectomy is around $1-2 \%[27,28]$. This rate was found to be $0.6 \%$ in our study. Surgical resection in gallbladder carcinomas is the only curative treatment [28]. There is consensus that simple cholecystectomy or LC is adequate for $\mathrm{pT} 1 \mathrm{a}$ tumours. Tumours at pT2 and higher stages require additional radical surgery, such as a hepatic S4a + S5 resection and hepatic pedunculated lymphadenectomy $[27,29,30]$.

\section{Conclusions}

Even when the appearance of gallbladder specimens is normal, histopathological assessment allows for early diagnosis of many unusual findings such as gallbladder cancer. Gallbladder specimens should be extracted in an endobag in patients with suspicious lesion in the gallbladder. Laparoscopic cholecystectomy was performed mostly in patients with acute and chronic cholecystitis. Open cholecystectomy was performed mostly in patients with gallbladder cancer and gangrenous cholecystitis. Emergency cholecystectomy was performed mostly in patients with acute and chronic active cholecystitis. Open cholecystectomy was performed in $39.5 \%$ of the patients undergoing emergency cholecystectomy, and a significant part of these operations were performed in the early years of our centre's laparoscopic experience.

\section{Conflict of interest}

The authors declare no conflict of interest.

\section{References}

1. De Reuver PR, van Dijk AH, Wennmacker SZ, et al. A randomized controlled trial to compare a restrictive strategy to usual care for the effectiveness of cholecystectomy in patients with symptomatic gallstones (SECURE trial protocol). BMC Surg 2016; 16: 46.

2. Zhang J, Lu Q, Ren YF, et al. Factors relevant to persistent upper abdominal pain after cholecystectomy. HPB (Oxford) 2017; 19 : 629-37.

3. Ansaloni L, Pisano M, Coccolini F, et al. 2016 WSES guidelines on acute calculous cholecystitis. World J Emerg Surg 2016; 11: 25.

4. Strasberg SM. Clinical practice. Acute calculous cholecystitis. N Engl J Med 2008; 358: 2804-11.

5. Abdelkader AM, Ali HE. Laparoscopic cholecystectomy for management of acute calculous cholecystitis within and after 3 days of symptom beginning: a retrospective study. Egypt J Surg 2018; 37: 46-52.

6. De Mestral C, Rotstein OD, Laupacis A, et al. A population-based analysis of the clinical course of 10,304 patients with acute cholecystitis, discharged without cholecystectomy. J Trauma Acute Care Surg 2013; 74: 26-30.

7. Yokoe M, Takada T, Strasberg SM, et al. TG13 diagnostic criteria and severity grading of acute cholecystitis (with videos). Hepatobiliary Pancreat Sci 2013; 20: 35-46.

8. Overby DW, Apelgren KN, Richardson W, et al.; Society of American Gastrointestinal and Endoscopic Surgeons. SAGES guidelines for the clinical application of laparoscopic biliary tract surgery. Surg Endosc 2010; 24: 2368-86.

9. Grass F, Cachemaille $M$, Blanc $C$, et al. Is standardized care feasible in the emergency setting? A case matched analysis of patients undergoing laparoscopic cholecystectomy. BMC Surg 2016; 16: 78.

10. Oymaci E, Ucar AD, Aydogan S, et al. Evaluation of affecting factors for conversion to open cholecystectomy in acute cholecystitis. Gastroenterology Rev 2014; 9: 336-41.

11. Knight JS, Mercer SJ, Somers SS, et al. Timing of urgent laparoscopic cholecystectomy does not influence conversion rate. Br J Surg 2004; 91: 601-4. 
12. Gallstone Disease: Diagnosis and Management of Cholelithiasis, Cholecystitis and Choledocholithiasis. National Institute for Health and Care Excellence, (UK) London 2014.

13. Thangavelu A, Rosenbaum S, Thangavelu D. Timing of cholecystectomy in acute cholecystitis. J Emerg Med 2018; 54: 892-7.

14. Ibrahim M, Sarvepalli S, Morris-Stiff G, et al. Gallstones: watch and wait, or intervene? Cleve Clin J Med 2018; 85: 323-31.

15. Yamashita Y, Takada T, Strasberg SM, et al. TG13 surgical management of acute cholecystitis. J Hepatobiliary Pancreat Sci 2013; 20: 89-96.

16. Onoe S, Kaneoka Y, Maeda A, et al. Feasibility of laparoscopic cholecystectomy for acute cholecystitis beyond $72 \mathrm{~h}$ of symptom onset. Updates Surg 2016; 68: 377-83.

17. Girgin S, Gedik E, Aldemir M, et al. Current treatment and surgery of acute cholecystitis. Turkiye Klinikleri J Surg Med Sci 2007; 3: 44-9.

18. Rajcok M, Bak V, Danihel L, et al. Early versus delayed laparoscopic cholecystectomy in treatment of acute cholecystitis. Bratisl Lek Listy 2016; 117: 328-31.

19. Aroori S, Mangan C, Reza L, et al. Percutaneous cholecystostomy for severe acute cholecystitis: a useful procedure in highrisk patients for surgery. Scand J Surg 2019; 108: 124-9.

20. Ambe PC, Kaptanis S, Papadakis M, et al. Cholecystectomy vs. percutaneous cholecystostomy for the management of critically ill patients with acute cholecystitis: a protocol for a systematic review. Syst Rev 2015; 4: 77.

21. Atar E, Bachar GN, Berlin S, et al. Percutaneous cholecystostomy in critically ill patients with acute cholecystitis: complications and late outcome. Clin Radiol 2014; 69: e247-52.

22. Kimura Y, Takada T, Kawarada Y, et al. Definitions, pathophysiology, and epidemiology of acute cholangitis and cholecystitis: Tokyo Guidelines. J Hepatobiliary Pancreat Surg 2007; 14: 15-26.

23. Kiriyama S, Takada T, Strasberg SM, et al. TG13 guidelines for diagnosis and severity grading of acute cholangitis (with videos). J Hepatobiliary Pancreat Sci 2013; 20: 24-34.

24. Molavi I, Schellenberg A, Christian F. Clinical and operative outcomes of patients with acute cholecystitis who are treated initially with image-guided cholecystostomy. Can J Surg 2018; 61: 195-9.

25. Gupta R, Kaman L, Dahiya D, et al. Effects of varying intraperitoneal pressure on liver function tests during laparoscopic cholecystectomy. J Laparoendosc Adv Surg Tech A 2013; 23: 339-42.

26. Avraamidou A, Marinis A, Asonitis S, et al. The impact of ischemic preconditioning on hemodynamic, biochemical and inflammatory alterations induced by intra-abdominal hypertension: an experimental study in a porcine model. Langenbecks Arch Surg 2012; 397: 1333-41.

27. Utsumi M, Aoki H, Kunitomo T, et al. Evaluation of surgical treatment for incidental gallbladder carcinoma diagnosed during or after laparoscopic cholecystectomy: single center results. BMC Res Notes 2017; 10: 56.

28. Isambert M, Leux C, Metairie S, et al. Incidentally-discovered gallbladder cancer: when, why and which reoperation? J Visc Surg 2011; 148: e77-84
29. Qadan M, Kingham TP. Technical aspects of gallbladder cancer surgery. Surg Clin North Am 2016; 96: 229-45.

30. Konstantinidis IT, Deshpande V, Genevay M, et al. Trends in presentation and survival for gallbladder cancer during a period of more than 4 decades: a single-institution experience. Arch Surg 2009; 144: 441-7.

Received: 25.04 .2019

Accepted: 30.06 .2019 